\title{
Associations between dietary habits and body mass index with gut microbiota composition and fecal water genotoxicity: an observational study in African American and Caucasian American volunteers
}

\author{
Volker Mai*1, Quintece M McCrary², Rashmi Sinha ${ }^{3}$ and Michael Glei ${ }^{4}$
}

Address: ${ }^{1}$ Microbiology and Cell Science, Emerging Pathogens Institute, University of Florida, Gainesville, FL, USA, ${ }^{2}$ Food Science and Technology, University of Maryland Eastern Shore, Princess Anne, MD, USA, ${ }^{3}$ DCEG, National Cancer Institute, Bethesda, MD, USA and ${ }^{4}$ Institute for Nutrition, Department for Nutritional Toxicology, Friedrich-Schiller-University, Jena, Germany

Email: Volker Mai* - vmai@ufl.edu; Quintece M McCrary - qmmccrary@umes.edu; Rashmi Sinha - sinhar@exchange.nih.gov; Michael Glei - Michael.Glei@uni-jena.de

* Corresponding author

Published: 21 October 2009

Nutrition Journal 2009, 8:49 doi:10.1186/1475-289/-8-49

This article is available from: http://www.nutritionj.com/content/8/I/49

(c) 2009 Mai et al; licensee BioMed Central Ltd.

This is an Open Access article distributed under the terms of the Creative Commons Attribution License (http://creativecommons.org/licenses/by/2.0), which permits unrestricted use, distribution, and reproduction in any medium, provided the original work is properly cited.
Received: 15 June 2009

Accepted: 21 October 2009

\begin{abstract}
Background: African Americans (AA) suffer from an increased incidence and mortality of colorectal cancer (CRC). Environmental exposures including dietary habits likely contribute to a high burden of CRC, however, data on the dietary habits of AA is sparse. Diet might change the composition and the activities of the intestinal microbiota, in turn affecting fecal genotoxicity/ mutagenicity that is thought to be associated with carcinogenesis.
\end{abstract}

Methods: We assessed dietary habits by food frequency questionnaire and by food records in 52 $\mathrm{AA}$ and $46 \mathrm{CA}$ residents of the Eastern Shore of MD. Fecal microbiota composition was determined using $16 \mathrm{~S}$ rRNA based methods and fecal genotoxicity measured using the Comet assay.

Results: AA reported an increased intake of heterocyclic amines and a decreased dietary intake of vitamins including vitamin $D(p<0.05)$ that correlated with differences in fecal microbiota composition but not fecal genotoxicity. Intake of dietary fiber, calcium, total fat and heterocyclic amines correlated with differences in microbiota composition. Total bacterial counts/g of stool and raw counts of Bacteroides were increased in AA. In contrast to a previous study, BMI was not associated with proportions of Bacteroides.

Conclusion: Dietary habits of African Americans, including increased HCA intake and decreased vitamin $D$ intake might at least partially contribute to $C R C$ through modifications of gut microbiota composition that result in changes of the intestinal milieu.

\section{Introduction}

Colorectal cancer (CRC) is thought to be strongly associated with environmental exposures including diet. Components ingested through the diet are a major source for exposure of the colonic epithelium to mutagenic compounds that may cause both initiation of cell transformation and tumor progression [1,2]. The objective of the current study was to determine if dietary habits, previ- 
ously shown to differ between African Americans (AA) and Caucasian Americans (CA), effect the composition of gut microbiota and result in differences in fecal water cytotoxicity/genotoxicity.

AA suffer from an increased incidence and mortality of CRC in comparison to CA (American Cancer Society: Statistics for 2008, http://www.cancer.org/docroot/stt/ stt_0.asp?from=fast). Although the underlying causes for these differences are not well established it is plausible that differences in dietary habits in AA affect the colonic environment by increasing exposure to mutagens directly as well as indirectly through changes in the composition of the metabolically active gut microbiota [3]. In a previous large study of associations between diet and CRC in AA and CA in North Carolina differences between the two racial groups were detected in the intake of micro- as well as macronutrients [4-6]. This study also suggested that associations between diet and CRC might differ between the two racial groups. One observation in the above study was an increased intake of heterocyclic amines (HCAs) by AA. HCAs such as 2-amino-1-methyl-6-phenyl-imidazo[4,5-b]pyridine (PhIP), and 2-amino-3,8-dimethylimidazo[4,5-f]quinoxaline (MeIQx), and also benzo[a]pyrene (Bap) a polycyclic aromatic hydrocarbon $(\mathrm{PAH})$, are possible humancarcinogens formed during meat cooking. Large amounts of HCA are formed with longer cooking times, internal temperatures of between $150^{\circ} \mathrm{C}$ and $200^{\circ} \mathrm{C}$, and greater external charring [7], typically achieved with cooking methods such as barbeque.

Humans harbor in their guts a complex intestinal microbiota that varies in its composition between individuals. Although recent studies have shed some light on the complexity of the gut microbiota in a limited number of individuals, the extent of microbiota diversity and associations with dietary habits are still poorly understood [8]. Tremendous advances in our understanding of the composition and activities of the gut microbiota have recently been made, however, we still do not fully understand the degree of complexity or the dynamics of the human gut microbiota $[9,10]$. It is now well established that the human gut microbiota is phylogenetically as well as metabolically very diverse and makes important contributions to the physiology of its human host $[11,12]$. Eloquent studies have shown communication between gut microbiota and the human host, a requirement of gut microbiota for appropriate priming and development of the immune system and associations between gut microbiota and obesity mediated by the induction/suppression of various human factors [13-17]. The host microbiota can have profound effects on nutrient acquisition and sequestering, immune priming and reactivity, as well as direct effects on carbohydrate and other compound levels in the systemic circulation $[18,19]$. The microbiota has long been suspected to be associated with health as well as with diseases including inflammatory bowel diseases and CRC, recent data supports an association between reduced microbiota diversity and Crohn's disease [20].

Fecal water, the water-soluble fraction obtained as the supernatant after high speed centrifugation of total feces, reflects the luminal content of both risk factors and protective factors [21]. Cytotoxicity/genotoxicity of fecal water is a useful biomarker in studying the impact of environmental factors on exposure of the gut to carcinogens and the modification of this exposure by dietary habits [22-24]. Cytotoxicity/genotoxicity of fecal water can be assessed in vitro by exposing cultured human colon cells, followed by assessment of cell viability and DNA damage in single cells by the Comet assay [25]. Fecal water genotoxicity has previously been shown to be related to colon carcinogenesis in animals [26]. In human studies, fecal water genotoxicity was higher after a diet rich in meat as compared to a diet enriched in fiber [27]. Supplementation with probiotic yoghurts has been shown to reduce fecal water genotoxicity [28]. There also appears to be an effect modification by smoking status as supplementation with bread enriched with prebiotics and antioxidants reduced the fecal water genotoxicity in non-smokers but not in smokers, an effect which differed by the status of GST M-polymorphisms [29].

In this study we investigated if differences in dietary habits between the two groups are associated with cytotoxicity/ genotoxicity of fecal water and with fecal microbiota composition.

\section{Materials and methods Study design}

Target population

We included subjects that were at least 40 years of age, self identified as being of AA or CA descent and able to provide informed consent and information regarding dietary history as well as basic demographic data. We excluded subjects that had a prior diagnosis of cancer (other than skin cancer); suffered from inflammatory bowel disease; had chronic diarrhea or acute diarrhea within the past 4 weeks; were hospitalized or used systemic antibiotics within the past 4 weeks. A total of 98 subjects, $52 \mathrm{AA}$ and 46 CA were enrolled. To evaluate associations between obesity and microbiota composition all 14 lean (BMI $<25)$ and 14 randomly chosen obese subjects (BMI >30) were selected. The study was approved by the Institutional Review Boards at UMB and UMES.

\section{Study logistics}

Subjects were approached about the study through local community groups. After enrollment, subjects received a study kit that included all questionnaires as well as a stool 
collection kit. After filling out the questionnaires subjects kept a four day food record and collected the first stool sample after its completion.

\section{Assessment of diet and medical history}

Subjects completed the self-administered Block 98 food frequency questionnaire (FFQ) that assessed their dietary habits [30], and a specific questionnaire assessing consumption of meat and its preparation (MMQ) [31]. Subjects also kept a food record of all foods and drinks consumed for four consecutive days. Medical history and demographic information was assessed using a scan able questionnaire specifically developed for this study.

\section{Stool collection}

After completing a four day food record subjects collected a freshly voided stool sample. The stool sample was transported to the laboratory in a plastic bag containing an ice pack within six hours. Upon arrival in the laboratory each sample was immediately homogenized and fixed for FISH analysis or frozen $-80^{\circ} \mathrm{C}$ for all other analyses.

\section{Analytical cohort}

From the 98 subjects that completed the study protocol we removed subjects with low quality dietary data, those that skipped more than 10 questions on the FFQ and those that reported a daily calorie intake of less than 400 or more than 5200 calories. $42 \mathrm{AA}$ and $40 \mathrm{CA}$ remained in the FFQ/MMQ analysis and $39 \mathrm{AA}$ and $38 \mathrm{AA}$ in the Food Record analysis. All 14 lean study subjects $(\mathrm{BMI}<25)$ and 14 randomly chosen obese subjects (BMI >30) were included in the studies of the association between microbiota and obesity.

\section{Microbiota analysis DNA Extraction}

DNA was isolated from $200 \mathrm{mg}$ of stool for each sample by using a modified QIAmp DNA Stool Mini kit (Qiagen, Cat. No. 51504, Valencia, CA). Noted modifications were the addition of 5 glass beads to the initial buffer solution to allow better homogenization of the stool while vortexing and the addition of $0.3 \mathrm{~g}$ zirconia beads (Biospec Products Inc., Cat. No. 11079101z, Bartlesville, OK) followed by 3 min of shaking in a Mini-BeadBeater (Glen Mills Inc., Clifton, NJ), prior to the addition of the Inhibit-EX tablet, to enhance the lysis of bacterial cell walls. Purified DNA samples were eluted in a final volume of $50 \mu \mathrm{l}$ and stored at $-70^{\circ} \mathrm{C}$ until analyzed.

Denaturing Gradient Gel Electrophoresis (DGGE) A 457-bp fragment from the V6 to V8 region of the bacterial 16S rDNA gene was amplified with primers U968-GC (5' CGC CCG GGG CGC GCC CCG GGC GGG GCG GGG GCA CGG GGG GAA CGC GAA GAA CCT TAC) and L1401 (5' GCG TGT GTA CAA GAC CC), as described by
Zoetendal et al. [32]. The GC clamp facilitates separation by DGGE. DGGE was performed in an $8 \%$ (wt/vol) polyacrylamide gel with a denaturing gradient ranging from $40 \%$ to $50 \%$ at the top and bottom of the gel, respectively (100\% denaturing conditions were defined as $7 \mathrm{M}$ urea and $40 \%$ formamide). After electrophoresis ( $16 \mathrm{~h}, 65 \mathrm{~V}$, $60^{\circ} \mathrm{C}$ ), the gels were stained with SYBER Green (Novex, San Diego, CA) and scanned/analyzed with Quantity One and Diversity Database software (Bio-Rad, Hercules, CA).

\section{Fluorescent in situ hybridization (FISH)}

Aliquots $(0.5 \mathrm{ml})$ of homogenized feces were added to PBS $(4.5 \mathrm{ml})$, and the samples were prepared for FISH analysis as described previously [33]. Briefly, the mixtures were processed by vortexing them with 3-5 glass beads for 2 min, removing fecal debris by centrifugation at low speed, fixing the bacteria-containing supernatant fluids overnight in PBS containing 3\% paraformaldehyde, and storing aliquots of the fixed bacterial preparations at $70^{\circ} \mathrm{C}$ until hybridization was performed. Hybridization was performed by applying aliquots $(10 \mu \mathrm{l})$ of appropriate dilutions of the fixed bacterial preparations to gelatincoated microscopic slides, fixing the specimens to the slides with 95\% ethanol, and hybridizing with $10 \mathrm{ng}$ of the appropriate probe/ $\mu \mathrm{l}$, using the conditions described previously [33-35]. The following probes were used: (i) Bac303 for Bacteroides and Prevotella [36], (ii) Erec482 for eubacteria, clostridia and ruminococci belonging to Clostridium cluster XIVa [33], (iii) Bif164 for bifidobacteria [37], (iv) LAB158 for lactic acid bacteria [38]. After briefly rinsing with distilled water, slides were air-dried rapidly with compressed air and mounted with Vectashield containing DAPI (4',6-diamidino-2-phenylindole) (Vector Labs, Cat. No. H-1200, Burlingame, CA). DAPI and Cy3/FITC positive cells were enumerated in a total of 12 fields at two different dilutions per sample at $100 \times$ magnification using a Zeiss axioscope-40 epifluorescenceequipped microscope (Zeiss, Jena, Germany). The proportions of the two bacterial groups were calculated by dividing the number positive for the specific probe by the total bacteria as determined by DAPI. DAPI was used as it allows for the enumeration of total bacteria without the need for a separate hybridization.

\section{Quantitative PCR ( $q P C R)$}

qPCR analysis was performed on a subset of 14 lean $(\mathrm{BMI}<25)$ and 16 obese subjects (BMI $>30)$ in duplicate using a qPCR Core kit (Eurogentec, Cat. No. RT-SN1005NR, San Diego, CA) on a Stratagene MX3000P (La Jolla, $\mathrm{CA})$ in $12.5 \mu \mathrm{l}$ reaction volumes consisting of $2 \mu \mathrm{l}$ DNA template (diluted 1:80 in water), $1 \times$ Reaction Buffer, 200 $\mu \mathrm{M}$ dNTP mix, $30 \mathrm{pM}$ forward and reverse primers, 0.025 $\mathrm{U} / \mu \mathrm{l}$ HotGoldStar Taq Polymerase, $1 \times$ SYBR Green dye, $30 \mathrm{nM}$ ROX passive reference dye (Stratagene, Cat. No. 600546, La Jolla, CA). The following primers and condi- 
tions were used: 1) all eubacteria (V3 F: 5'-CCTACGGGAGGCAGCAG-3';R: 5'-ATTACCGCGGCTGCTGG-3', $\left.56^{\circ} \mathrm{C}, 3 \mathrm{mM} \mathrm{MgCl}_{2}\right)$; 2) Bacteroides-Prevotella-Porphyromonas group (Bac $\mathrm{F}$ : 5'-GGTGTCGGCTTAAGTGCCAT3'; R: 5'-CGGA(C/T)GTAAGGGCCGTGC-3', $68^{\circ} \mathrm{C}, 3 \mathrm{mM}$ $\mathrm{MgCl}_{2}$ ); Clostridium coccoides-Eubacterium rectale group (Erec F: 5'-CGGTACCTGACTAAGAAGC-3'; R: 5'AGTTT(C/T)ATTCTTGCGAACG-3', $55^{\circ} \mathrm{C}, 4 \mathrm{mM} \mathrm{MgCl}_{2}$ ) [39]. qPCR conditions were as follows: $10 \mathrm{~min}$ at $95^{\circ} \mathrm{C}$ followed by 40 cycles of $95^{\circ} \mathrm{C}$ for $30 \mathrm{~s}$, annealing for 1 min (see primer specific temperature above), and extension at $72^{\circ} \mathrm{C}$ for $30 \mathrm{~s}$.

qPCR standard curves covering the range observed in the samples were generated using a lab internal DNA standard derived from a human stool sample. The proportions of the two groups were calculated by dividing the number positive for the specific primer set by the total number of bacteria determined using the universal V3 primer set.

\section{Fecal water analysis}

Fecal samples were homogenized using a glass rod. For preparation of the fecal water (FW), the feces were centrifuged $\left(18500 \mathrm{rpm}\right.$ for $2 \mathrm{~h}$ at $\left.4^{\circ} \mathrm{C}\right)$ and the supernatants were collected. After a further centrifugation step (13000 $\mathrm{rpm}$ for $10 \mathrm{~min}$ at $4^{\circ} \mathrm{C}$ ) to obtain a clear solution, the liquid phases were quantified, the $\mathrm{pH}$-values were determined with a $\mathrm{pH}$ meter, and the samples were aliquoted and stored at $-80^{\circ} \mathrm{C}$ until use.

\section{Human tumor cell line HT29}

The human colon carcinoma cell line HT29, obtained from the American Tissue Culture Collection (Rockville, MD, USA), was used to test toxicity of the FWs [40]. Cells were kept frozen in liquid Nitrogen until thawed and grown at $37^{\circ} \mathrm{C}$ in a $(95 \%)$ humidified incubator $(5 \%$ $\mathrm{CO}_{2}$ ) in Dulbecco's Modified Eagle Medium (DMEM, Gibco BRL, Eggenstein, Germany) supplemented with $10 \%$ fetal calf serum, penicillin $(50 \mathrm{U} / \mathrm{mL})$ and streptomycin $(50 \mu \mathrm{g} / \mathrm{mL})$. Passages 22 to 29 (cytotoxicity and genotoxicity studies) and 40-50 (challenge assay) were used for the experiments.

\section{Cytotoxicity assay}

To determine the effective dose of FW the cell suspensions were initially incubated with $5 \%, 10 \%$ or $20 \%$ of FW. All following assays were performed using $20 \%$ concentration to reach a measurable DNA damage level. FW was added to $100 \mu \mathrm{l}$ cell suspension containing $4 \times 10^{5} \mathrm{HT} 29$ cells. The suspensions were incubated for $30 \mathrm{~min}$ in a shaking water bath at $37^{\circ} \mathrm{C}$ and cytotoxicity was determined using the trypan blue exclusion assay.

\section{Genotoxicity assay}

DNA damage was measured in $1 \times 10^{5}$ cells suspended in low melting point agarose on microscope slides with the single cell microgel electrophoresis assay, also known as the "Comet assay" [41] as previously described [42]. 50 images/slide were evaluated by measuring the percentage of fluorescence in the tail.

\section{Challenging treatment to evaluate the antigenotoxic potential}

The Comet assay was also used to determine if a pretreatment with fecal water leads to a modified genotoxic effect of $\mathrm{H}_{2} \mathrm{O}_{2}$. Cells were pretreated with $20 \%$ fecal water (30 $\min , 37^{\circ} \mathrm{C}$ ) and subsequently incubated with $75 \mu \mathrm{M}$ $\mathrm{H}_{2} \mathrm{O}_{2}$ for $5 \mathrm{~min}$ at $4^{\circ} \mathrm{C}$. Viabilities were determined with the trypan blue exclusion test and the remaining cells were analyzed with the Comet assay as described above.

\section{Statistics}

Multivariate regression analysis (SAS) was used to explore associations between multiple exposure factors and microbiota composition. Shannon Wiener index was used to calculate microbiota diversity of the DGGE profiles. Unpaired t-test and one-way ANOVA (Microsoft Excel version 2003) were used to calculate means and variation and for establishing two-sided significance levels ( $\mathrm{p}<$ $0.05)$.

\section{Results \\ Dietary analysis}

After removal of subjects with low quality data 82 subjects, $42 \mathrm{AA}$ and $40 \mathrm{CA}$, were retained in the analytical cohort for the FFQ based analysis of differences in dietary habits between the two racial groups. Both groups were similar in age and gender distribution. AA had a higher mean weight and body mass index but lower income and lower level of education (Table 1). AA consumed a diet

Table I: Study demographics in African American (AA) and Caucasian American (CA) participants

\begin{tabular}{lcc}
\hline & AA & CA \\
\hline$\#$ & 52 & 46 \\
\hline Mean age (years) & 51.2 & 52.3 \\
\hline Sex (male) & $27 \%$ & $35 \%$ \\
\hline Mean weight & $1991 \mathrm{~b}$ & $177 \mathrm{lb}$ \\
\hline Mean BMI & 32 & 28 \\
\hline Income <30,000US & $48 \%$ & $33 \%$ \\
\hline College degree & $33 \%$ & $61 \%$ \\
\hline
\end{tabular}

$\mathrm{BMI}$ is body mass index (weight $/$ height $^{2}$ in $\mathrm{kg} / \mathrm{m}^{2}$ ). 
lower in the percent of calories from fat and higher in percent of calories from carbohydrates (Table 2). AA also had a lower intake of supplemental vitamins including vitamin D. Although total intake of HCA did not differ between the groups, the intake of MeIQx and PhIP, two HCA formed during meat preparation at high temperature, was increased in AA $(\mathrm{p}<0.05)$.

Data from the four day food records mostly supported the findings from the FFQ analysis, albeit fewer associations reached statistical significance (data not shown). Specifically, the differences in percent calories from fat and carbohydrates as well as the decreased intake of vitamin $D$ in AA were confirmed with this secondary tool.

\section{Fecal water analysis}

FW analysis was performed in a subset of $21 \mathrm{AA}$ and $22 \mathrm{CA}$ subjects for which we had a sufficient amount of fecal sample. We successfully extracted an average of $18.6 \% \mathrm{FW}$ from the fecal samples. No difference in yield was observed between the samples from AA and CA. The mean $\mathrm{pH}$ of the FW was 6.9, the observed difference between AA (6.7) and CA (7.1) was borderline significant $(\mathrm{p}=0.05)$ when both genders were combined and significant in females alone (AA: 6.7, CA: 7.2; p < 0.05). To determine the appropriate dose of fecal water for the genotoxicity assay, the cell suspensions were incubated with 5\%, 10\% or $20 \% \mathrm{FW}$. FW induced DNA damage in a dose dependent manner $(p=0.052)$. However, even at the highest dose of $20 \% \mathrm{FW}$, which was used in all subsequent studies, we observed only a weak increase in measurable DNA breaks.

We observed no differences in fecal water induced cytotoxicity or genotoxicity between the two racial groups as both, the tail intensity and the viability of the HT 29 cells showed no significant differences between the two groups (Figure 1). When we analyzed the proportion of undamaged cells with a tail intensity $\leq 6 \%$ as an alternative measure of genotoxicity we detected only a small and statistically insignificant difference between the two racial groups that suggested a trend towards slightly reduced genotoxicity in fecal waters from AA. Furthermore the results showed a significantly increased genotoxicity in FW from females that was not associated with cell viability (Figure 1). BMI, age and diet including fat intake and dietary levels of heterocyclic amines were not associated with either genotoxicity or viability (data not shown). The large variation associated with the genotoxicity assay would not have allowed us to detect any small or medium effects with the limited number of subjects included in this study. To evaluate potential protective effects of FW we analyzed the effects of preincubation of HT29 cells with fecal water before challenge with $\mathrm{H}_{2} \mathrm{O}_{2}$ and measurement of its genotoxicity, using the remaining fecal waters from
Table 2: Differences in diet between AAs and CAs as determined by FFQ

\begin{tabular}{|c|c|c|c|}
\hline & AA (42) & CA (40) & p-value \\
\hline Total calories (kcal) & 1918 & $186 \mid$ & 0.8 \\
\hline Protein (g) & 65 & 69 & 0.6 \\
\hline Fat (g) & 77 & 82 & 0.6 \\
\hline Carbohydrates (g) & 248 & 214 & 0.19 \\
\hline$\%$ kcal from protein & 13.8 & 15.1 & 0.09 \\
\hline$\%$ kcal from fat & 35.2 & 39.2 & 0.01 \\
\hline$\% \mathrm{kcal}$ from carbs & 52.4 & 46.2 & $<0.01$ \\
\hline Dietary fiber (g) & 17.6 & 16.7 & 0.7 \\
\hline Fruit (servings) & 1.5 & 1.5 & 0.9 \\
\hline Vegetable(servings) & 3.1 & 3.8 & 0.24 \\
\hline Dairy (servings) & 0.68 & 1.43 & $<0.01$ \\
\hline Calcium (mg) & 608 & 774 & 0.07 \\
\hline \multicolumn{4}{|l|}{ Supplements } \\
\hline Calcium (mg) & 108 & 418 & $<0.01$ \\
\hline Magnesium (mg) & 19 & 42 & 0.02 \\
\hline Vitamin A (IU) & 1200 & 2700 & 0.03 \\
\hline Vitamin C (mg) & 140 & 380 & $<0.01$ \\
\hline Vitamin D (IU) & 77 & 166 & 0.02 \\
\hline Vitamin E (a-TE) & 46 & 157 & $<0.01$ \\
\hline \multicolumn{4}{|l|}{ Heterocyclic amines } \\
\hline Total (ng/day) & 190 & 128 & 0.1 \\
\hline MelQx (ng/day) & 47 & 25 & 0.04 \\
\hline PhIP (ng/day) & 126 & 78 & 0.07 \\
\hline Dimelqx (ng/day & 2.8 & 2.1 & 0.2 \\
\hline Bap (ng/day) & 14 & 22 & 0.1 \\
\hline
\end{tabular}

$\mathrm{PhIP}$ is 2-amino-I-methyl-6-phenyl-imidazo[4,5-b]pyridine, MelQx is 2-amino-3,8-dimethylimidazo[4,5-f]quinoxaline, Dimelqx is 2-amino3,4,8-trimethylimidazo[4,5-f]quinoxaline Bap is benzo[a]pyrene. 


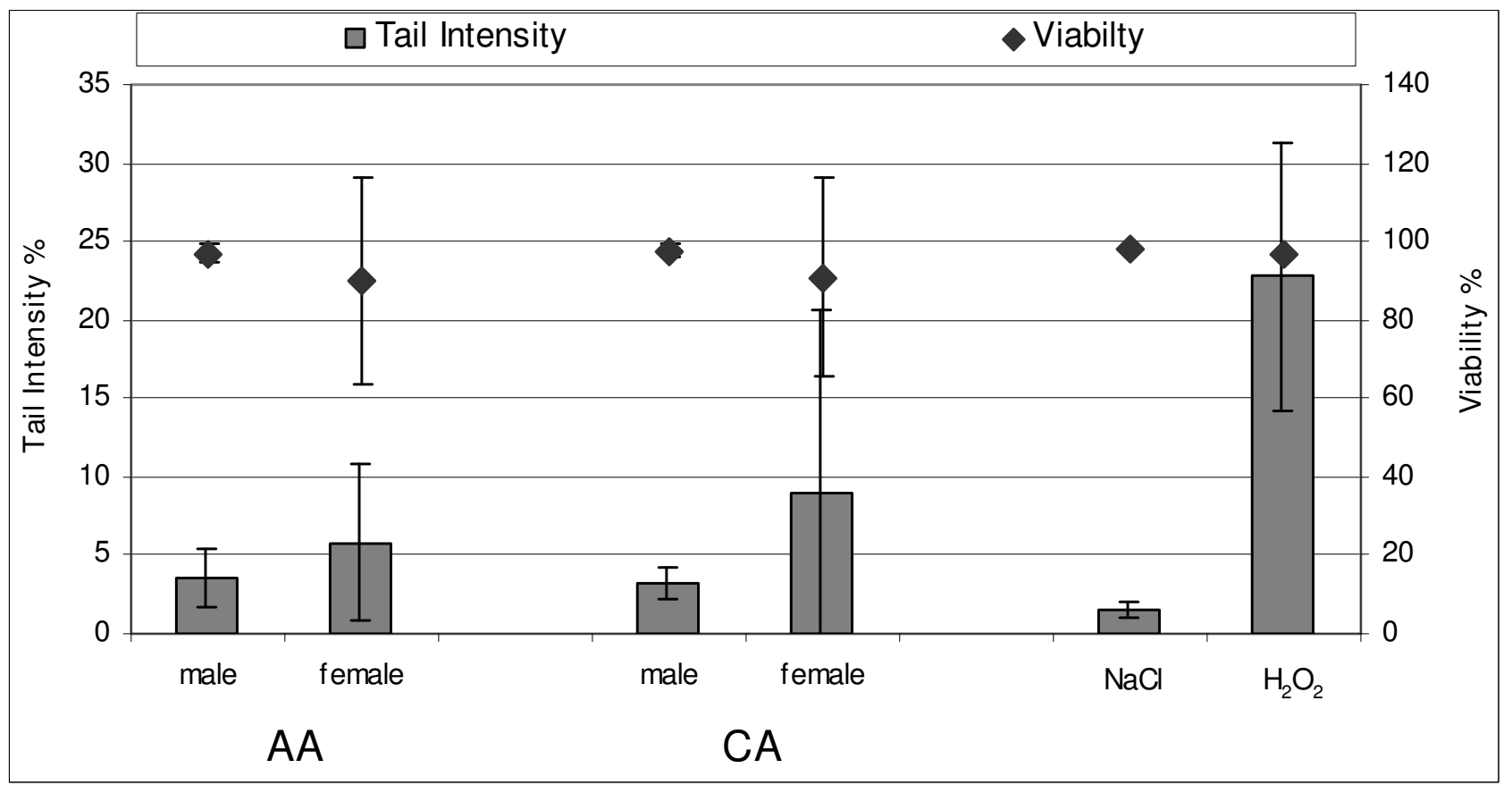

\section{Figure I}

DNA damage and viability of HT 29 cells after incubation with FW. AAs $(n=2 I)$, CAs $(n=22)$, males and females. $\mathrm{NaCl}$-- negative control; $\mathrm{H}_{2} \mathrm{O}_{2}$-- positive control.

33 subjects. Although $\mathrm{H}_{2} \mathrm{O}_{2}$ clearly induced DNA breaks preincubation of the HT29 cells with fecal waters did not affect the degree of DNA damage (data not shown).

\section{Microbiota analysis}

We first analyzed overall microbiota composition by qualitative DGGE profiling, an efficient but crude method for assessing microbiota diversity (a measure of species richness and their distribution). We did not detect a difference in overall diversity with any of our measured variables (data not shown). Based on DGGE profiles, the mean Shannon-Wiener diversity index in all samples, a measure of overall microbiota diversity, was 2.3 with a SD of 0.2 and a range between 2.0 and 2.7. In contrast, quantitative microbiota analysis by FISH revealed some differences between the two racial groups. The total number of bacteria/g of stool was higher in AA when compared to CA (Figure 2). These differences, although statistically significant on the decimal scale, were not significant after log transformation. Although total number of Bacteroidetes that hybridized to our probe were increased in AA (Figure 2) the proportions of Bacteroidetes or Clostridia cluster XIVa (Firmicutes) that were targeted with the respective probes did not differ between AA and CA. We detected suggestive associations between dietary intake and quantities of bacterial groups. Subjects that consumed high amounts of calories from fat harbored fewer Clostridia. Consumption of dietary fiber was positively associated with numbers of LAB, which are thought to be beneficial to health. Grain fiber and fiber from fruits and veggies but not fiber from beans appeared associated with LAB (data not shown). Subjects with higher intake of HCAs had higher amounts of Clostridia cluster XIVa. All of these potential associations between exposure of interest and microbiota reached statistical significance $(\mathrm{p}<0.05)$ only in the initial analyses of raw data, however, after log transformation of bacterial counts to achieve a more normal distribution none of the associations remained significant.

When we analyzed the proportions of Bacteroidetes and Clostridia cluster XIVa (Firmicutes) in all 14 lean study subjects $(\mathrm{BMI}<25)$ compared to 14 matched obese subjects $(\mathrm{BMI}>30)$, we failed to detect an association with BMI by either FISH (Figure 3a). The apparent lack of associations between obesity and the proportions of Bacteroidetes and Clostridia cluster XIVa in our study population was confirmed using a second quantitative approach, qPCR (Figure 3b). 


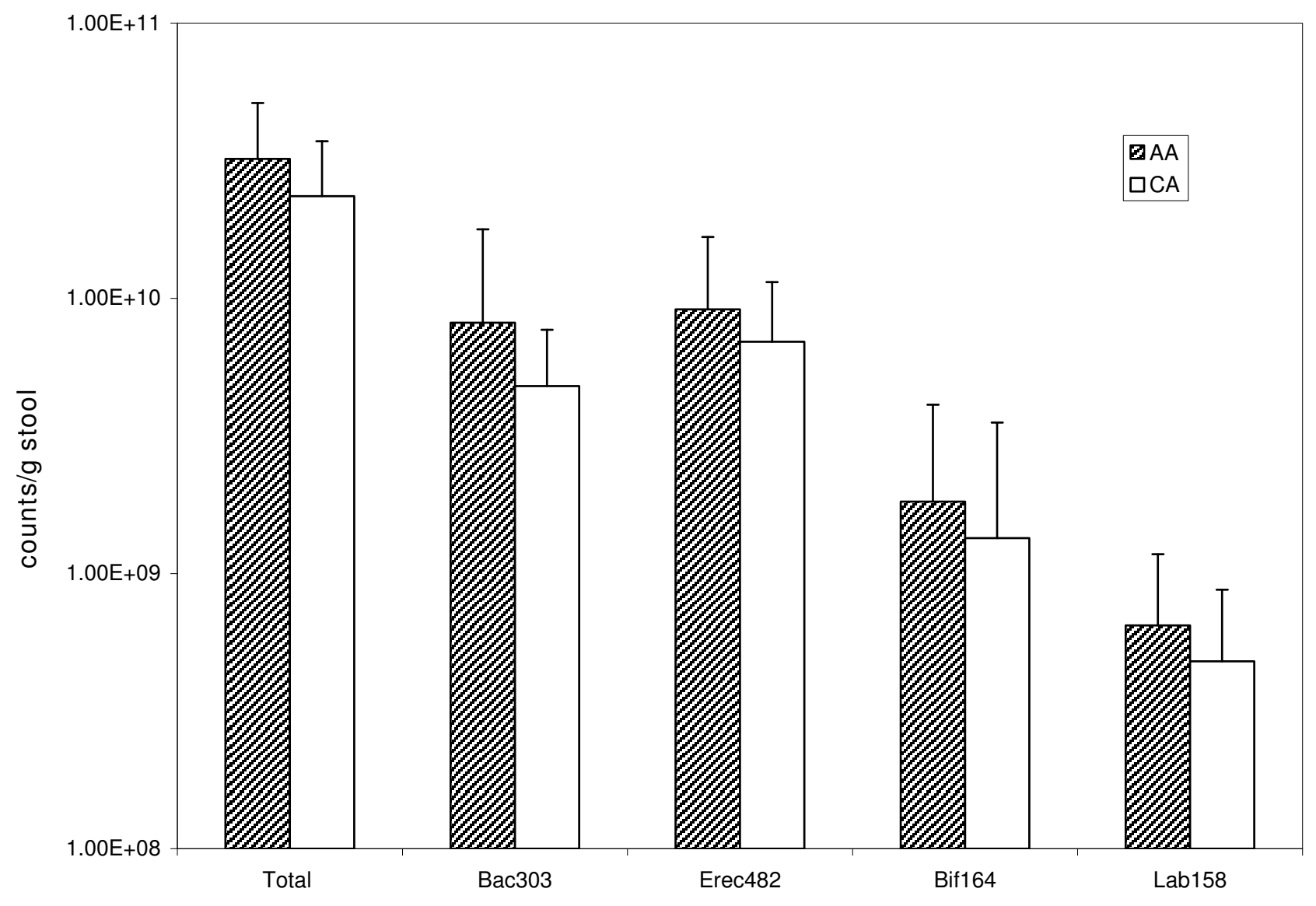

Figure 2

Comparison of microbiota between AA and CA. Fixed stool samples were hybridized with probes directed against Bacteroidetes (Bac 303), Clostridium Cluster XIVa (Erec482), Bifidobacteria (Bif I64) and Lactic Acid bacteria (Lab I 58) and enumerated by FISH as described in Materials and Methods. Total bacterial counts were determined using DAPI.

\section{Discussion}

Our analysis of differences in dietary habits between AA and CA is consistent with previous reports that suggested an increased intake of HCAs and a decreased intake of micronutrients in AA [4-6]. Although our study was limited in size, the agreement of two independent dietary assessment methods (FFQ and food record) increases confidence in our observation. As both HCA intake and vitamin D levels have been associated with carcinogenesis $[7,43]$ there appears to be an opportunity for dietary prevention to reduce the burden of cancer in AA.

Exposure of HT29 cells to FW from subjects in this study did induce DNA damage. However, although the two groups differed in various exposures, including BMI and dietary habits, we did not detect significant differences in responses to FW from the two groups. Our study was limited in size and measurement of cytotoxicity and genoto- xicity included a large degree of variation. The observation that FW from females appear to exhibit higher genotoxicity is not consistent with the hypothesis that FW genotoxicity is associated with CRC risk, as US females have lower CRC rates than males. Although we used twice as much fecal water $(20 \%)$ compared to earlier studies [27,29], we observed only a weak increase in measurable DNA breaks. Future studies of associations between environmental factors and FW genotoxicity should be designed in larger human cohorts preferably with controlled exposures to reduce variation.

The observation that total bacterial counts/g of stool and numbers of Bacteroides counts were increased in AA is suggestive rather than confirmatory. Soft large stools of rural Africans have been considered as representing low colorectal cancer risk in early observations of the effects of dietary fiber intake [44]. A higher water content of stools 
a)

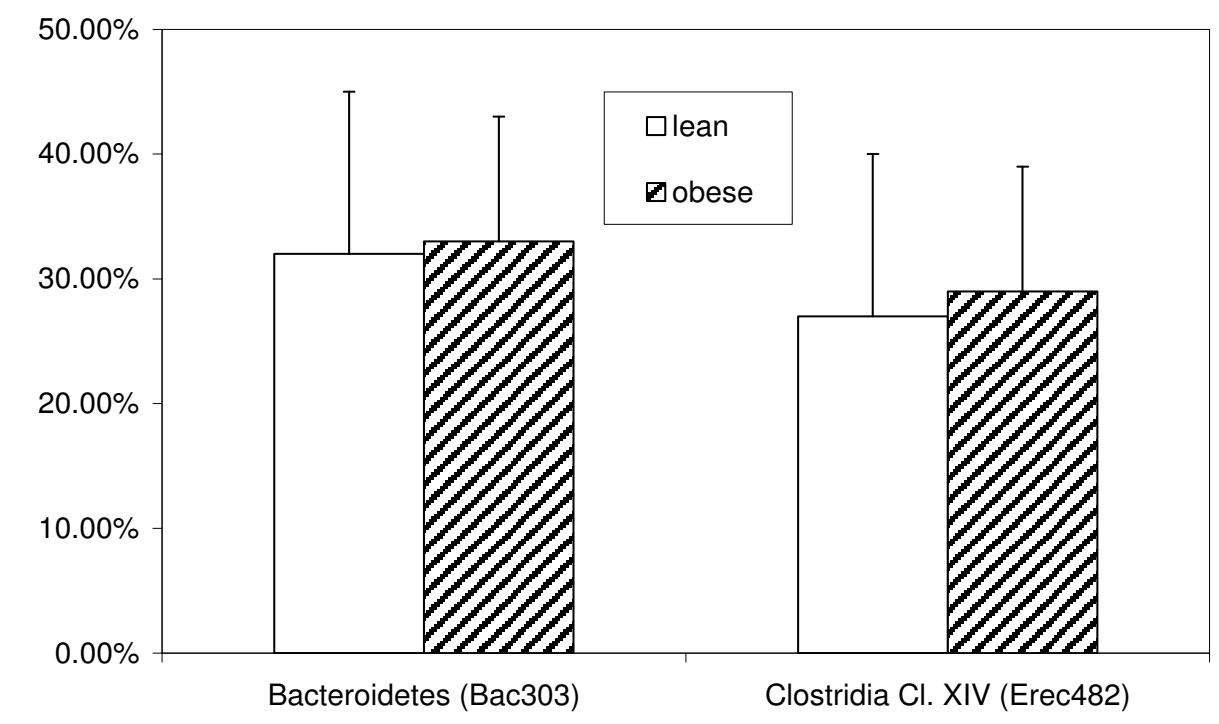

b)

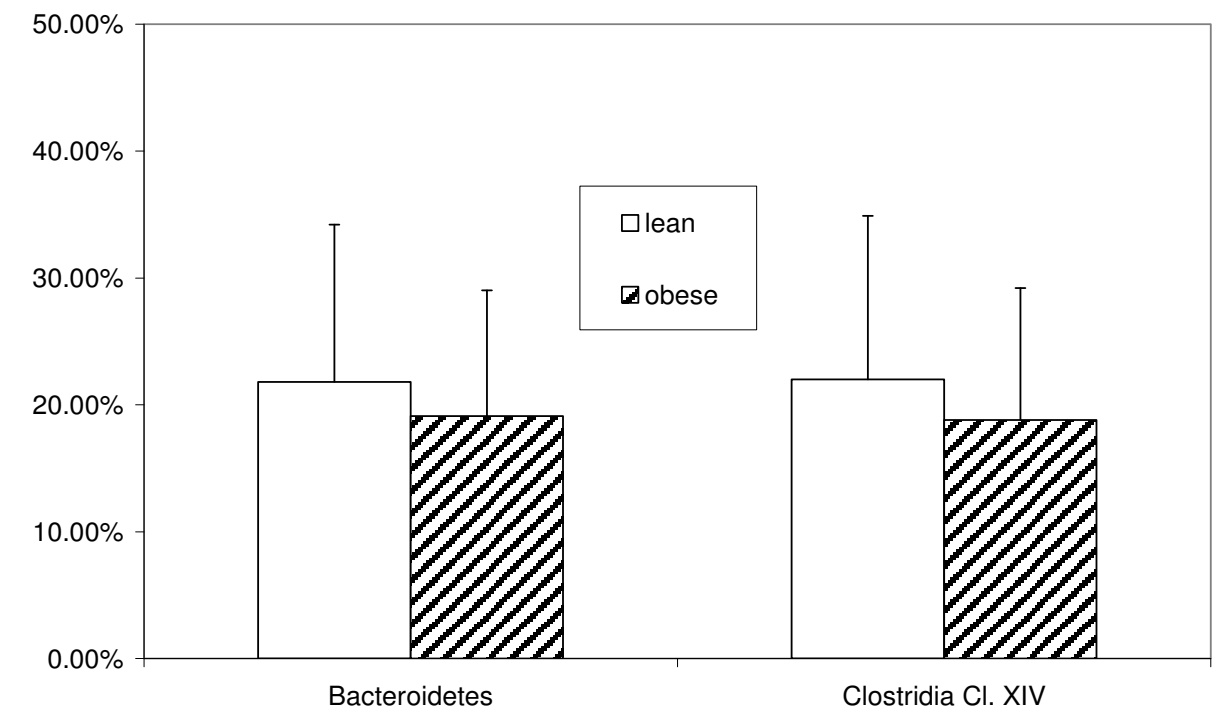

Figure 3

Proportions of bacteroidetes and Clostridia Cluster XIVa in obese vs. lean subjects as determined by a) FISH and b) qPCR analysis. 
would reduce bacterial densities and thus harder stools might contain larger densities of bacteria. We collected only one spot stool sample from each subject and variation in microbiota composition over time appears significant $[45,46]$. The same qualifications need to be made when interpreting our findings that intake of fiber, HCA and calories from fat affected microbiota composition. Although we have shown earlier that dietary interventions in mice as well as in humans can affect microbiota composition [45,47], similar data from observational studies is sparse [3]. There has been significant recent interest in potential associations between gut microbiota and obesity, specifically a decrease proportion of bacteria belonging to the Bacteroidetes among obese [15,48-50]. Our data does not support that hypothesis as AA in our study had a higher BMI that correlated with higher, not lower, numbers of Bacteroidetes. A detailed quantitative study in a subset of lean and obese subjects from this study also failed to detect such an association. We used a different methodology (FISH and qPCR) compared to the at best semi-quantitative 16S rRNA based analysis frequently used by other groups. Our probes and primers admittedly do not cover Bacteroidetes species perfectly and due to differences in methodology results can't be compared directly to $16 \mathrm{~S}$ rRNA based studies. However, recent work from other groups also appears inconsistent with a proposed association between lower proportions of Bacteroidetes and obesity $[17,51]$. The ongoing Human Microbiota Roadmap Project is aimed at improving our understanding of normal microbiota composition and its potential associations with health and disease http:// nihroadmap.nih.gov/hmp/. Our observations are consistent with the hypothesis that diet mediated differences in gut microbiota contribute to the observed increased risk of colorectal cancer in AA. Because diseases such as CRC can change the intestinal environment with likely impacts on microbiota composition, future studies with prospectively collected stool samples will be required to link microbiota composition with disease risk.

\section{Competing interests}

The authors declare that they have no competing interests.

\section{Authors' contributions}

VM designed the study, helped with study logistics, analyzed the data and wrote the manuscript. QM enrolled subjects, collected samples and performed the microbiota analyses. RS helped with the design of the dietary assessment and contributed to the HCA analysis. MG helped wit the study design, supervised the mutagenicity studies and wrote respective eparts of the manuscript. All authors read and approved the final manuscript.

\section{Acknowledgements}

This work was supported by a pilot grant from the Maryland Special Population Network. Work in the lab of Dr. Mai is supported by ACS grant
MRSGT CCE-10730I. We thank B.L. Zobel (deceased 2008) for discussion regarding study design and interpretation of the findings. We thank $\mathrm{Dr}$. C. Boushey for help with the food record data.

\section{References}

I. Branca F, Hanley AB, Pool-Zobel BL, Verhagen H: Biomarkers in Disease and Health. Br J Nutr 200I, 86:S55-S92.

2. World Cancer Research Fund: Food, Nutrition, and the Prevention of Cancer: A Global Perspective. American Institute for Cancer Research, Washington, D C 2007.

3. Mai V: Dietary modification of the intestinal microbiota. Nutr Rev 2004, 62:235-242.

4. Satia-Abouta J, Galanko JA, Martin CF, Potter JD, Ammerman A, Sandler RS: Associations of micronutrients with colon cancer risk in African Americans and whites: results from the North Carolina Colon Cancer Study. Cancer Epidemiol Biomarkers Prev 2003, I 2:747-754.

5. Satia-Abouta J, Galanko JA, Potter JD, Ammerman A, Martin CF, Sandler RS: Associations of total energy and macronutrients with colon cancer risk in African Americans and Whites: results from the North Carolina colon cancer study. Am J Epidemiol 2003, I 58:95I-962.

6. Satia-Abouta J, Galanko JA, Martin CF, Ammerman A, Sandler RS: Food groups and colon cancer risk in African-Americans and Caucasians. Int J Cancer 2004, 109:728-736.

7. Butler LM, Sinha R, Millikan RC, Martin CF, Newman B, Gammon MD, Ammerman AS, Sandler RS: Heterocyclic amines, meat intake, and association with colon cancer in a population-based study. Am J Epidemiol 2003, I 57:434-445.

8. Zoetendal EG, Vaughan EE, De Vos WM: A microbial world within us. Mol Microbiol 2006, 59:1639-1650.

9. Mai V, Stine OC, Morris JG Jr: Timing in collection of stool samples. Science 2005, 310:1 I18.

10. Mai V, Draganov PV: Recent advances and remaining gaps in our knowledge of associations between gut microbiota and human health. World J Gastroenterol 2009, I 5:8I-85.

11. Eckburg PB, Bik EM, Bernstein CN, Purdom E, Dethlefsen L, Sargent M, Gill SR, Nelson KE, Relman DA: Diversity of the human intestinal microbial flora. Science 2005, 308:1635-1638.

12. Gill SR, Pop M, Deboy RT, Eckburg PB, Turnbaugh PJ, Samuel BS, Gordon Jl, Relman DA, Fraser-Liggett CM, Nelson KE: Metagenomic analysis of the human distal gut microbiome. Science 2006, 3 12:1355-1359.

13. Hooper LV, Wong MH, Thelin A, Hansson L, Falk PG, Gordon Jl: Molecular analysis of commensal host-microbial relationships in the intestine. Science 200I, 29I:88I-884.

14. Huurre A, Kalliomaki M, Rautava S, Rinne M, Salminen S, Isolauri E: Mode of Delivery - Effects on Gut Microbiota and Humoral Immunity. Neonatology 2007, 93:236-240.

15. Ley RE, Backhed F, Turnbaugh P, Lozupone CA, Knight RD, Gordon Jl: Obesity alters gut microbial ecology. Proc Natl Acad Sci USA 2005, 102: I 1070-I I075.

16. Backhed F, Manchester JK, Semenkovich CF, Gordon JI: Mechanisms underlying the resistance to diet-induced obesity in germ-free mice. Proc Natl Acad Sci USA 2007, 104:979-984.

17. Zhang H, Dibaise JK, Zuccolo A, Kudrna D, Braidotti M, Yu Y, Parameswaran P, Crowell MD, Wing R, Rittmann BE, et al.: Human gut microbiota in obesity and after gastric bypass. Proc Natl Acad Sci USA 2009, 106:2365-2370.

18. Guarner F, Malagelada JR: Gut flora in health and disease. Lancet 2003, 36 I:512-519.

19. Marchesi J, Shanahan F: The normal intestinal microbiota. Curr Opin Infect Dis 2007, 20:508-5I3.

20. Manichanh C, Rigottier-Gois L, Bonnaud E, Gloux K, Pelletier E, Frangeul L, Nalin R, Jarrin C, Chardon P, Marteau P, et al.: Reduced diversity of faecal microbiota in Crohn's disease revealed by a metagenomic approach. Gut 2006, 55:205-2II.

21. DeKok TMCM, van Maanen JMS: Evaluation of fecal mutagenicity and colorectal cancer risk. Mutation Res 2000, 463:53-I0I.

22. Rafter J, Chin SM, Andersson AM, Alder R, Eng W, Bruce R: Cellular toxicity of faecal water depends on diet. Am J Clin Nutr 1987, 45:559-563.

23. Glinghammer B, Venturi M, Rowland IR, Rafter J: Shift from a dairy product-rich to a dairy product-free diet: influence on cyto- 
toxicity and genotoxicity of fecal water - potential risk factors for colon cancer. Am J Clin Nutr 1997, 66: I 277- 1282

24. Klinder A, Karlsson PC, Clune Y, Hughes R, Glei M, Rafter JJ, Rowland I, Collins JK, Pool-Zobel BL: Fecal water as a non-invasive biomarker in nutritional intervention: comparison of preparation methods and refinement of different endpoints. Nutr Cancer 2007, 57: I58-167.

25. Collins AR: The comet assay for DNA damage and repair: principles, applications, and limitations. Mol Biotechnol 2004, 26:249-26I.

26. Klinder A, Forster A, Caderni G, Femia AP, Pool-Zobel BL: Fecal water genotoxicity is predictive of tumor-preventive activities by inulin-like oligofructoses, probiotics (Lactobacillus rhamnosus and Bifidobacterium lactis), and their synbiotic combination. Nutr Cancer 2004, 49: 144-I55.

27. Rieger MA, Parlesak A, Pool-Zobel BL, Rechkemmer G, Bode C: Diets high in fat and meat, but low in fiber increase the genotoxic potential of fecal water. Carcinogenesis 1999 , 20:2317-2326

28. Oberreuther-Moschner DL, Jahreis G, Rechkemmer G, Pool-Zobel BL: Dietary intervention with the probiotics Lactobacillus acidophilus 145 and Bifidobacterium longum 9 I 3 modulates the potential of human faecal water to induce damage in HT29clone I 9A cells. Br J Nutr 2004, 91 :925-932.

29. Glei M, Habermann N, Osswald K, Seidel C, Persin C, Jahreis G, PoolZobel BL: Assessment of DNA damage and its modulation by dietary and genetic factors in smokers using the Comet assay: a biomarker model. Biomarkers 2005, 10:203-217.

30. Subar AF, Thompson FE, Kipnis V, Midthune D, Hurwitz P, McNutt S, Mclntosh A, Rosenfeld S: Comparative validation of the Block, Willett, and National Cancer Institute food frequency questionnaires: the Eating at America's Table Study. Am J Epidemiol 200I, 154:1089-1099.

31. Cantwell M, Mittl B, Curtin J, Carroll R, Potischman N, Caporaso N, Sinha R: Relative validity of a food frequency questionnaire with a meat-cooking and heterocyclic amine module. Cancer Epidemiol Biomarkers Prev 2004, I 3:293-298.

32. Zoetendal EG, Akkermans AD, De Vos WM: Temperature gradient gel electrophoresis analysis of I6S rRNA from human fecal samples reveals stable and host-specific communities of active bacteria. Appl Environ Microbiol 1998, 64:3854-3859.

33. Franks AH, Harmsen HJ, Raangs GC, Jansen G], Schut F, Welling GW: Variations of bacterial populations in human feces measured by fluorescent in situ hybridization with group-specific 165 rRNA-targeted oligonucleotide probes. Appl Environ Microbiol 1998, 64:3336-3345

34. Harmsen HJ, Wildeboer-Veloo AC, Grijpstra J, Knol J, Degener JE, Welling GW: Development of I6S rRNA-based probes for the Coriobacterium group and the Atopobium cluster and their application for enumeration of Coriobacteriaceae in human feces from volunteers of different age groups. Appl Environ Microbiol 2000, 66:4523-4527.

35. Harmsen HJ, Raangs GC, He T, Degener JE, Welling GW: Extensive set of I6S rRNA-based probes for detection of bacteria in human feces. Appl Environ Microbiol 2002, 68:2982-2990.

36. Manz W, Amann R, Ludwig W, Vancanneyt M, Schleifer KH: Application of a suite of I6S rRNA-specific oligonucleotide probes designed to investigate bacteria of the phylum cytophagaflavobacter-bacteroides in the natural environment. Microbiology 1996, 142: 1097-I I06.

37. Langendijk PS, Schut F, Jansen GJ, Raangs GC, Kamphuis GR, Wilkinson $\mathrm{MH}$, Welling GW: Quantitative fluorescence in situ hybridization of Bifidobacterium spp. with genus-specific 165 rRNA-targeted probes and its application in fecal samples. Appl Environ Microbiol 1995, 6 I:3069-3075.

38. Harmsen HJM, Elferich P, Schut F, Welling GW: A I6S rRNA-targeted probe for detection of Lactobacilli and Enterococci in faecal samples by fluorescent in situ hybridization. Microbial Ecology in Health and Disease 1999, I 1:3-12.

39. Rinttila T, Kassinen A, Malinen E, Krogius L, Palva A: Development of an extensive set of 165 rDNA-targeted primers for quantification of pathogenic and indigenous bacteria in faecal samples by real-time PCR. J Appl Microbiol 2004, 97: I I 66- I I 77.

40. Rousset M: The human colon carcinoma cell lines HT-29 and Caco-2: two in vitro models for the study of intestinal differentiation. Biochimie 1986, 68:1035-1040.
4I. Singh NP, McCoy MT, Tice RR, Schneider EL: A simple technique for quantitation of low levels of DNA damage in individual cells. Exp Cell Res 1988, 175:184-191.

42. Glei M, Kirmse A, Habermann N, Persin C, Pool-Zobel BL: Bread enriched with green coffee extract has chemoprotective and antigenotoxic activities in human cells. Nutr Cancer 2006, 56:182-192

43. Giovannucci E: Vitamin $D$ and cancer incidence in the Harvard cohorts. Ann Epidemiol 2009, 19:84-88.

44. Burkitt DP: Epidemiology of cancer of the colon and rectum. Cancer 197I, 28:3-13.

45. Mai V, Katki HA, Harmsen H, Gallaher D, Schatzkin A, Baer DJ, Clevidence $B$ : Effects of a controlled diet and black tea drinking on the fecal microflora composition and the fecal bile acid profile of human volunteers in a double-blinded randomized feeding study. J Nutr 2004, 134:473-478.

46. Dethlefsen L, Huse S, Sogin ML, Relman DA: The pervasive effects of an antibiotic on the human gut microbiota, as revealed by deep 16S rRNA sequencing. PLoS Biol 2008, 6:e280.

47. Mai V, Colbert LH, Perkins SN, Schatzkin A, Hursting SD: Intestinal microbiota: a potential diet-responsive prevention target in ApcMin mice. Mol Carcinog 2007, 46:42-48.

48. Backhed F, Ding H, Wang T, Hooper LV, Koh GY, Nagy A, Semenkovich CF, Gordon Jl: The gut microbiota as an environmental factor that regulates fat storage. Proc Natl Acad Sci USA 2004, 101:157|8-15723.

49. Turnbaugh PJ, Ley RE, Mahowald MA, Magrini V, Mardis ER, Gordon JI: An obesity-associated gut microbiome with increased capacity for energy harvest. Nature 2006, 444: 1027-1031.

50. Ley RE, Turnbaugh PJ, Klein S, Gordon Jl: Microbial ecology: human gut microbes associated with obesity. Nature 2006, 444: $1022-1023$

5I. Duncan SH, Lobley GE, Holtrop G, Ince J, Johnstone AM, Louis P, Flint $\mathrm{HJ}$ : Human colonic microbiota associated with diet, obesity and weight loss. Int J Obes (Lond) 2008, 32:1720-1724.
Publish with BioMed Central and every scientist can read your work free of charge

"BioMed Central will be the most significant development for disseminating the results of biomedical research in our lifetime. "

Sir Paul Nurse, Cancer Research UK

Your research papers will be:

- available free of charge to the entire biomedical community

- peer reviewed and published immediately upon acceptance

- cited in PubMed and archived on PubMed Central

- yours - you keep the copyright
BioMedcentral 